\title{
PENGARUH MEDIA PEMBELAJARAN DAN MOTIVASI BELAJAR TERHADAP HASIL BELAJAR KIMIA
}

\author{
ASEP MULYANA \\ SMKN 1 Gunungputri \\ e-mail : pesbukbaba@gmail.com
}

\begin{abstract}
ABSTRAK
Penelitian ini bertujuan untuk mengetahui sejauh mana media pembelajaran (dalam hal ini penggunaan aplikasi Edmodo) dan Motivasi siswa terhadap hasil belajar kimia. Penelitian ini menggunakan metode eksperimen. Sampel berjumlah 70 siswa dilakukan dengan menggunakan teknik purporsive sampling, dari siswa kelas X SMK Negeri di Kabupaten Bogor. Pengumpulan data dilakukan dengan tes tertulis dan angket penelitian. Penelitian ini merupakan penelitian kuasi eksperimen dengan desain faktorial $2 \times 2$. Teknik analisis data yang digunakan adalah analisis varian (Anava) dua jalur dengan taraf signifikansi ( $\alpha$ ) 0,05. Hasil penelitian menunjukkan: 1) Terdapat pengaruh yang signifikan penggunaan media belajar terhadap hasil belajar kimia pada siswa di SMK Negeri Kab. Bogor. 2) Terdapat pengaruh yang signifikan tingkat motivasi terhadap hasil belajar kimia pada siswa SMK Negeri di Kab. Bogor. 3) Terdapat pengaruh Interaktif yang signifikan media Pembelajaran dan motivasi terhadap hasil belajar kimia pada siswa SMK Negeri Kab. Bogor.
\end{abstract}

Kata kunci: Media Pembelajaran, Edmodo, Motivasi Belajar, Hasil Belajar Kimia

\section{ABSTRACT}

This study aims to determine the extent to which learning media (in this case the use of the Edmodo application) and students' motivation towards chemistry learning outcomes. This research is using experimental method. A sample of 70 students was conducted using purporsive sampling technique, from class X SMK Negeri in Bogor Regency. Data was collected by means of written tests and research questionnaires. This research is a quasiexperimental study with a $2 \times 2$ factorial design. The data analysis technique used is a two-way analysis of variance (Anova) with a significance level $(\alpha)$ of 0.05 . The results showed: 1$)$ There was a significant effect of the use of learning media on chemistry learning outcomes for students at SMK Negeri Kab. Bogor. 2) There is a significant effect of motivation level on chemistry learning outcomes for State Vocational High School students in Kab. Bogor. 3) There is a significant interactive effect of learning media and motivation on chemistry learning outcomes for students of SMK Negeri Kab. Bogor.

Keywords: Learning Media, Edmodo, Learning Motivation, Chemistry Learning Outcomes

\section{PENDAHULUAN}

SMK sebagai subsistem pendidikan nasional yang bertanggung jawab dalam penyiapkan SDM tingkat menengah yang handal, dituntut untuk menerapkan prinsip demand driven, job oriented, dan dual based program, yang berorientasi kepada kebutuhan pasar bahkan mampu mengembangkan inovasi untuk mempengaruhi perubahan kebutuhan pasar sehingga dapat mewujudkan kepuasan pelanggan. SMK bertujuan menyiapan siswa untuk dapat mengisi lapangan kerja serta mampu bersikap profesional. Sesuai dengan bentuknya, sekolah menengah kejuruan menyelenggarakan program-program pendidikan yang disesuaikan dengan jenis-jenis lapangan kerja.

Dalam Struktur Kurikulum SMK pelajaran Kimia berada pada kelompok C (pemintan) dengan alokasi waktu 3 jam pelajaran perminggu. Kimia merupakan ilmu yang rumit akan pemahaman- pemahaman, dari pemahaman yang sangat sederhana, hingga pemahaman yang kompleks, serta pemahaman yang abtraks, sehingga diperlukan pemahaman yang benar terhadap konsep dasar yang membangun konsep tersebut. 
Dalam kenyataanya siswa SMKN memiliki kewajiban untuk melaksanakan Praktek Kerja di Industri yang menuntut belajar di lingkungan industri selama 3-6 bulan. Kegiatan Prakerin initentu mengganggu dalam pelaksanaan KBM yang lain salah satunya pelajaran Kimia yang masih dianggap sebagai salah satu pelajaran yang sukar dan sulit untuk di pahami, apalagi dengan tidak adanya pertemuan tatap muka seperti Prakerin ini. Siswa sebagai salah salah satu unsur berpengaruh terhadap keberhasilan belajar memiliki faktor internal dan eksternal. Salah satu faktor internal dari sisi siswa secara psikologis adalah adanya motivasi untuk mendapatkan hasil belajar. Sementara yang menjadi faktor eksternal adalah faktor instrumental, yaitu faktor yang keberadaan dan penggunaannya dirancang guru sesuai dengan hasil belajar yang diharapkan. Faktor ini diharapkan dapat berfungsi sebagai sarana untuk terciptanya tujuan-tujuan belajar, termasuk didalamnya adalah media pembelajaran.

Media pembelajaran yang dianggap dapat mengatasi masalah kurangnya efektifitas pembelajaran karena terpotong kegiatan praktek adalah dengan menyediakan media pembelajaran menggunakan e-learning berbasis Edmodo. Media Pembelajaran ini merupakan media pembelajaran berbasis jaringan internet sehingga dapat diakses kapan dan dimana saja, selama hardware-software memadai dan jaringan internetnya tersedia. Sehingga diharapkan media pembelajaran ini dapat mengatasi permasalahan ruang dan waktu, karena dapat diakses kapan dan dimana saja selama memiliki akses internet.

Dengan memanfaatkan kemajuan teknologi informasi (TI) diharapkan pendidikan akan menjadi lebih baik serta fleksibel, baik dalam sistem yang hendak dikembangkan, materi yang dapat diakses siswa dan guru, media pembelajaran atau media instruksional dan proses pembelajaran yang akan diterapkan serta bagaimana mencari alternatif solusi bila ditemukan hambatan dari siswa dan guru atau penyelenggara pendidikan, termasuk didalamnya kendala pertemuan secara fisik dikelas.

Media adalah segala sesuatu yang dapat digunakan untuk menyalurkan pesan dan dapat merangsang pikiran, dapat membangkitkan semangat, perhatian dan kemauan siswa sehingga dapat mendorong terjadinya proses pembelajaran dalam diri siswa (Angkowo dan Kosasih, 2007:11). Media dalam dunia pendidikan digunakan sebagai sarana yang berfungsi menyalurkan pengetahuan dari Guru kepada peserta didik. Media pembelajaran mencakup semua sumber yang diperlukan untuk melakukan komunikasi dalam pembelajaran, bentuknya bisa berupa perangkat keras (hardware), seperti computer, TV, projector, dan perangkat lunak (software) yang digunakan pada perangkat keras itu. Edmodo adalah platform pembelajaran gratis dan aman yang tersedia di www.edmodo.com. Website ini terlihat Mirip dengan Facebook, tapi jauh lebih pribadi dan aman untuk lingkungan belajar. Edmodo adalah pembelajaran berbasis jejaring sosial yang aman dan gratis dalam memudahkan guru untuk membuat dan mengelola kelas virtual sehingga siswa dapat terhubung dengan teman sekelas dan guru kapan saja dan dimana saja. Edmodo adalah platform pembelajaran sosial untuk guru, siswa, dan orang tua. Guru juga mampu memposting nilai, tugas dan kuis kepada siswa. Siswa dapat mengirimkan pekerjaan rumah dan melihat nilai dan komentar mereka.

Menurut Clayton Alderfer dalam H. Nashar (2004:42) "Motivasi belajar adalah kecenderungan siswa dalam melakukan kegiatan belajar yang didorong oleh hasrat untuk mencapai prestasi atau hasil belajar sebaik mungkin. Adapun faktor-faktor yang mempengaruhi motivasi belajar terhadap siswa ada berbagai macam. Menurut Sardiman (2007:92), bahwa yang mempengaruhi motivasi belajar pada siswa adalah: tingkat motivasi belajar, tingkat kebutuhan belajar, minat dan sifat pribadi. Keempat faktor tersebut saling mendukung dan timbul pada diri siswa sehingga tercipta semangat belajar untuk melakukan aktivitas sehingga tercapai tujuan pemenuhan kebutuhannya.

\section{METODE PENELITIAN}

Penelitian ini merupakan quasi experiment research atau penelitian eksperimen semu, bertujuan untuk melihat perbedaan hasil belajar siswa dengan menggunakan media pembelajaran konvensional $\left(\mathrm{A}_{1}\right)$ dan hasil belajar siswa dengan menggunakan media 
pembelajaran Edmodo $\left(\mathrm{A}_{2}\right)$, dengan memperhatikan motivasi siswa yang tinggi $\left(\mathrm{B}_{1}\right)$ dan motivasi siswa yang rendah $\left(\mathrm{B}_{2}\right)$. penelitian yang digunakan adalah factorial design atau rancangan factorial 2x2, seperti terlihat pada tabel 1 dibawah ini.

Tabel 1. Disain faktorial $2 \times 2$

\begin{tabular}{|l|c|c|}
\hline \multirow{2}{*}{ Motivasi (B) } & \multicolumn{2}{|c|}{ Media Pembelajaran } \\
\cline { 2 - 3 } & Edmodo $\left(\mathrm{A}_{1}\right)$ & $\begin{array}{l}\text { Konvensional } \\
\left(\mathrm{A}_{2}\right)\end{array}$ \\
\hline Tinggi $\left(\mathrm{B}_{1}\right)$ & $\mathrm{Y}_{11}$ & $\mathrm{Y}_{12}$ \\
\hline Rendah $\left(\mathrm{B}_{2}\right)$ & $\mathrm{Y}_{21}$ & $\mathrm{Y}_{22}$ \\
\hline
\end{tabular}

Keterangan :

$\mathrm{A}_{1} \quad=$ Media Pembelajaran Edmodo

$\mathrm{A}_{2}=$ Media Pembelajaran Konvensional

$\mathrm{B}_{1} \quad=$ Motivasi Tinggi

$\mathrm{B}_{2} \quad=$ Motivasi Rendah

$\mathrm{Y}_{11}=$ Hasil belajar kimia siswa dengan media pembelajaran Edmodo dan motivasi belajar tinggi

$\mathrm{Y}_{12}=$ Hasil belajar kimia siswa dengan media pembelajaran konvensional dan motivasi belajar tinggi

$\mathrm{Y}_{21}=$ Hasil belajar kimia siswa dengan media pembelajaran Edmodo dan motivasi belajar rendah

$\mathrm{Y}_{22}=$ Hasil belajar kimia siswa dengan media pembelajaran konvensional dan motivasi belajar rendah.

Penelitian dilaksanakan di SMK N 1 Gunungputri, sampel dalam penelitian ini dilakukan dengan menggunakan teknik purporsive sampling, dengan sample penelitian sebanyak 70 siswa terdiri dari kelas X Kimia Industri yang terbagi dalam 2 kelompok kelas, yaitu kelompok dengan pendekatan pembelajaran menggunakan media pembelajaran Edmodo dan Kelompok dengan pendekatan pembelajaran menggunakan media konvensional.

Instrumen dalam penelitian ini adalah tes hasil belajar dan angket motivasi belajar. Tes hasil belajar menggunakan tes tertulis dalam bentuk tes pilihan ganda (multiple choice test). Jumlah seluruh soal sebanyak 25 butir dengan lima alternatif pilihan jawaban. Skor 1 untuk jawaban benar dan skor 0 untuk jawaban salah. Jumlah skor jawaban benar akan dikali 4, sehingga diperoleh skor minimal adalah 0 dan skor maksimal 100. Angket yang digunakan dalam penelitian ini adalah angket tertutup dengan 42 pernyataan. Kriteria penyususnan angket menggunakan skala likert yang terdiri atas lima kategori alternatif jawaban, sehingga diperoleh skor minimal adalah 42 dan skor maksimal 210.

Teknik analisis data yang digunakan dalam penelitian ini adalah teknik statistik deskriptif. Penelitian ini menggunakan Anova dua jalur untuk analisis datanya. Sebelum dilakukan Anova dua jalur, terlebih dahulu dilakukan uji prasyarat analisis yang terdiri dari uji normalitas dan uji homogenitas. Apabila uji prasyarat analisis terpenuhi, maka uji hipotesis dapat dilakukan.

\section{HASIL DAN PEMBAHASAN}

\section{Hasil}

Penelitian ini bertujuan untuk mengetahui apakah ada perbedaan hasil belajar dari siswa yang mempelajari materi yang sama dengan menggunakan dua media pembelajaran, juga dengan mempertimbangkan perbedaan motivasi belajar siswa. Pelaksanaan penelitian ini 
melibatkan 2 kelas $\mathrm{X}$ kimia yang masing-masing beranggota 35 siswa dengan perlakuan berbeda, satu sebagai kelas kontrol yaitu X kimia 2 dan X Kimia 2 sebagai kelas eksperimen.

Sebelum penelitian dimulai siswa diminta untuk mengisi kuisioner tentang motivasi belajar siswa, untuk mengukur tingkat motivasi belajar masing-masing siswa. Sebelum tes tersebut dipakai untuk mengumpulkan data, maka tes tersebut harus diujicobakan dahulu untuk mendapatkan data penelitian yang valid dan reliabel.

Selanjutnya dilaksanakan pengambilan data motivasi belajar dengan menggunakan kuisioner. Berdasar hasil kuisioner ini dari seluruh siswa yakni 70 siswa diperoleh hasil sebagai berikut

Tabel 2. Jumlah siswa pada masing-masing kelompok

\begin{tabular}{|c|c|c|}
\hline \multirow{2}{*}{ Motivasi (B) } & \multicolumn{2}{|c|}{ Media Pembelajaran } \\
\hline & Edmodo $\left(\mathrm{A}_{1}\right)$ & Konvensional $\left(\mathrm{A}_{2}\right)$ \\
\hline Tinggi $\left(B_{1}\right)$ & $\begin{array}{c}\mathbf{Y}_{11} \\
\text { Menggunakan Media Edmodo } \\
\text { dengan motivasi belajar tinggi } \\
22 \text { Siswa }\end{array}$ & $\begin{array}{c}\text { Y12 Menggunakan Media } \\
\text { konvensional dengan motivasi } \\
\text { belajar tinggi } \\
18 \text { Siswa }\end{array}$ \\
\hline Rendah $\left(\mathrm{B}_{2}\right)$ & $\begin{array}{c}\text { Y21 Menggunakan Media } \\
\text { Edmodo dengan motivasi } \\
\text { belajar rendah } \\
13 \text { Siswa }\end{array}$ & $\begin{array}{c}\text { Y22 Menggunakan Media } \\
\text { konvensional dengan motivasi } \\
\text { belajar rendah } \\
17 \text { Siswa }\end{array}$ \\
\hline
\end{tabular}

Dari pengelompokan tinggi rendahnya motivasi kemudian dilaksanakan 2 kali pembelajaran, sesuai dengan kelompok kelas perlakuan. Selanjutnya dilaksanakan post test untuk mendapatkan nilai dan digunakan sebagai data hasil belajar.

Selanjutnya dengan menggunakan bantuan aplikasi spss ver. 20.0 for windows diperoleh descriptive statistic seperti tabel 3

Tabel 3. Tabel Deskriptif statistik untuk masing-masing Subjek Descriptive Statistics

\begin{tabular}{|c|c|c|c|c|}
\hline Perlakuan & Motivasi & Mean & Std. Deviation & $\mathrm{N}$ \\
\hline \multirow{3}{*}{ Kelas Eksperimen } & Motivasi Tinggi & 85,82 & 12,078 & 22 \\
\hline & Motivasi rendah & 67,38 & 15,735 & 13 \\
\hline & Total & 78,97 & 16,098 & 35 \\
\hline \multirow{3}{*}{ Kelas Kontrol } & Motivasi Tinggi & 59,33 & 13,106 & 18 \\
\hline & Motivasi rendah & 57,88 & 18,768 & 17 \\
\hline & Total & 58,63 & 15,880 & 35 \\
\hline \multirow{3}{*}{ Total } & Motivasi Tinggi & 73,90 & 18,207 & 40 \\
\hline & Motivasi rendah & 62,00 & 17,881 & 30 \\
\hline & Total & 68,80 & 18,892 & 70 \\
\hline
\end{tabular}

Berdasar tabel 6 diatas siswa dengan menggunakan media Edmodo dan memliki motivasi tinggi memiliki rata-rata nilai sebesar 85,82 sebanyak 22 siswa, dan nilai rata-rata untuk siswa yang memiliki motivasi rendah memiliki rata-rata nilai 67,38, terdiri dari 13 siswa. 
Untuk siswa menggunakan media konvensional dan memiliki motivasi tinggi ada pada 59,33 sebanyak 18 orang dan yang memiliki motivasi rendah nilai rat-ratanya 57,88 terdiri dari 17 siswa.

Sementara untuk Instrumen uji hasil belajar terdapat dua uji prasyarat yaitu uji normalitas dan uji homogenitas. Untuk uji normalitas dilakukan dengan teknik uji KolmogorovSmirnov dengan bantuan aplikasi Spss ver. 20.0 diperoleh hasil seperti Tabel 4

Tabel 4. Hasil Uji Normalitas Data dengan Program SPSS 20.0

One-Sample Kolmogorov-Smirnov Test

\begin{tabular}{|ll|r|}
\hline & & \multicolumn{1}{|c|}{ Hasil Belajar } \\
\hline Kimia
\end{tabular}

a. Test distribution is Normal.

b. Calculated from data.

Berdasarkan tabel 2 diatas hasil pengujian yang diperoleh terlhat nilai $p$-value atau Asymp.Sig (2-tailed) $=0,719>0,05$ artinya data yang kita miliki data yang terdistribusi normal. Selain itu normal atau tidaknya data juga dapat dilihat dari hasil uji normalitas data dengan Normal P-P Plots sebagai berikut:

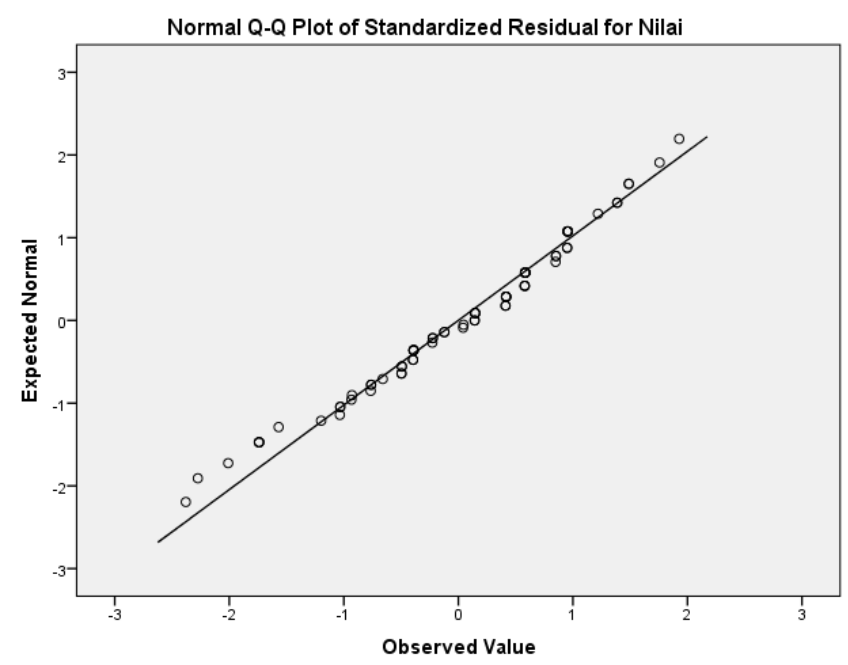

Gambar 1. Plot kenormalan data

Uji pra penelitian dalam penelitian ini adalah uji homogenitas kelas. Uji homogenitas digunakan untuk mengetahui apakah sampel penelitian berasal dari populasi yang terdistribusi normal atau tidak. dengan hasil sebagai berikut

Tabel 5. Hasil Uji Homogenitas menggunakan SPSS 20.0 Test of Homogeneity of Variances

Hasil Belajar Kimia

\begin{tabular}{|c|c|c|c|}
\hline Levene Statistic & df1 & df2 & Sig. \\
\hline 2.338 & 1 & 68 & .131 \\
\hline
\end{tabular}


Berdasarkan tabel 5. dapat diketahui bahwa nilai signifikansinya adalah 0,131, karena memiliki nilai signifikansi lebih dari 0,05 yakni 0,131 > 0,05 sehingga data tersebut dapat dikatakan homogen. Jadi kedua kelas yang dijadikan penelitian adalah kelas yang homogen.

Tabel 6. Tests of Between-Subjects Effects

Dependent Variable: Hasil Belajar Kimia

\begin{tabular}{|c|c|c|c|c|c|}
\hline Source & $\begin{array}{l}\text { Type III Sum } \\
\text { of Squares }\end{array}$ & $\mathrm{df}$ & $\begin{array}{l}\text { Mean } \\
\text { Square }\end{array}$ & $\mathrm{F}$ & Sig. \\
\hline Corrected Model & $10037,086^{a}$ & 3 & 3345,695 & 15,135 & ,000 \\
\hline Intercept & 308866,249 & 1 & 308866,249 & 1397,191 & ,000 \\
\hline Perlakuan & 5470,055 & 1 & 5470,055 & 24,744 & ,000 \\
\hline Motivasi & 1670,049 & 1 & 1670,049 & 7,555 & 008 \\
\hline $\begin{array}{l}\text { Perlakuan * } \\
\text { Motivasi }\end{array}$ & 1218,163 & 1 & 1218,163 & 5,510 & ,022 \\
\hline Error & 14590,114 & 66 & 221,062 & & \\
\hline Total & 355968,000 & 70 & & & \\
\hline Corrected Total & 24627,200 & 69 & & & \\
\hline
\end{tabular}

Dari tabel 6. diatas juga dapat dilihat pada corrected model, dapat dijelaskan bahwa semua variable independen (Media, Motivasi dan interaksi media dengan motivasi) secara bersamasama terhadap variabel dependen (hasil belajar). Apabila signifikansi (Sig.) $<0,05 \alpha$ (alfa) $=$ signifikan. Dalam tabel diatas nilai sig. $=0,000$. Nilai $R$ Squared sebesar 0.408 terdapat pengaruh sebesar $40.8 \%$ (tingkat sedang) antara semua variable bebas terhadap variabel terikat.

Dari hasil output uji hipotesis dengan anava dua Jalur dapat dilihat pada table 8. table Tests of Between-subjects Effects menunjukkan:

1. Kelas perlakuan dengan media Edmodo memiliki nilai signifikansi 0,000, maka $0,000<0,05, H_{0}$ ditolak dan nilai $F_{\text {hitung }}=24,744 \geq F_{\text {tabel }}=3,99$ maka $H_{0}$ ditolak. Sehingga disimpulkan bahwa ada pengaruh signifikan penggunaan media terhadap hasil belajar kimia.

2. Nilai signifikansi tingkat motivasi adalah 0,008 , maka $0,008<0,05, H_{0}$ ditolak dan nilai $F_{\text {hitung }}=7,555 \geq F_{\text {tabel }}=3,99$ maka $H_{0}$ ditolak.

Sehingga disimpulkan bahwa ada pengaruh signifikan motivasi belajar terhadap hasil belajar kimia.

3. Nilai signifikansi media pembelajaran dan tingkat motivasi adalah 0,022 , maka 0 , $022<0,05, \mathrm{H}_{0}$ ditolak dan nilai $F_{\text {hitung }}=5,510 \geq F_{\text {tabel }}=3,99$ maka $H_{0}$ ditolak.

Sehingga disimpulkan bahwa ada pengaruh interaksi yang signifikan media Pembelajaran dan motivasi belajar terhadap hasil belajar kimia.

\section{Pembahasan}

Motivasi belajar merupakan stimulasi atau rangsangan agar melakukan sesuatu perilaku belajar. Media Edmodo merupakan upaya yang dilakukan guru agar anak didik kita mau atau berkeinginan untuk melaksanakan proses belajar. Untuk mengetahui tingkat motivasi yang dimiliki siswa dalam kegiatan belajar mengajar maka dibuat instrumen penelitian berbentuk nontes dengan skala linkert, merupakan suatu alat untuk mengukur nilai sikap, minat dan 
perhatian yang disusun dalam bentuk pernyataan yang dinilai oleh responden dan hasilnya dalam bentuk rentangan nilai sesuai dengan kriteria yang ditentukan. (Arikunto;2006)

Sebelum test dilaksanakan terlebih dahulu dilakukan uji coba untuk menguji prasyarat terhadap perangkat uji angket motivasi belajar dan hasil belajar kimia, uji coba dilaksanakan di SMK Negeri 1 Cileungsi kelas X-1 Multi Media yang berjumlah 35 orang. Instrumen kuisioner terdiri dari 42 pernyataan sikap yang mana siswa memberikan tanda cek $(\sqrt{ })$ sebagai gambaran sesuai dengan yang mereka rasakan, Yaitu ; $\mathrm{SL}=$ Selalu, $\mathrm{SR}=$ Sering, KK=Kadang-kadang, SS= Sesekali, dan TP=Tidak Pernah. (Arikunto :2006)

Sebagai dasar pengambilan keputusan apakah suatu item valid atau tidak maka digunakan uji validitas product moment pearson correlation, adapun dasar pengambilan keputusan dalam uji ini adalah dengan cara membandingkan nilai sig. (2-tailed) dengan probabilitas 0,05 Dari hasil uji validitas terhadap perangkat angket motivasi dari 42 pertanyaan ada 5 item pernyataan yang tidak valid, sehingga yang digunakan hanya 37 item pertanyaan. (Supardi:2016).

Agar alat uji ini menjadi suatu alat yang dapat dipercaya maka dilakukan Uji reabilitas, sehingga kita dapat mengetahui apakah butir soal yang diujikan reliabel dalam memberikan hasil pengukuran. Untuk menguji reliabilitas instrumen peneliti melakukannya melalui metode Alpha-Cronbach. Perhitungan uji validitas menggunakan program komputer SPSS 20.0 for windows dan diperoleh hasil pengujian sebagai berikut:

\section{Tabel 7. Hasil Perhitungan Reliabilitas menggunakan SPSS 20.0} Case Processing Summary

\begin{tabular}{|rl|r|r|}
\hline & & $\mathrm{N}$ & \multicolumn{1}{c|}{$\%$} \\
\hline \multirow{3}{*}{ Cases } & Valid & 35 & 100,0 \\
& Excludeda & 0 &, 0 \\
& Total & 35 & 100,0 \\
\hline
\end{tabular}

a. Listwise deletion based on all variables in the procedure.

Reliability Statistics

\begin{tabular}{|r|r|}
\hline $\begin{array}{c}\text { Cronbach's } \\
\text { Alpha }\end{array}$ & N of ltems \\
\hline, 929 & 37 \\
\hline
\end{tabular}

Berdasarkan data output Reability Statistic, diketahui nilai Cronbach's Alpha adalah sebesar 0,929. Nilai tersebut kemudian akan kita bandingkan dengan nilai $r$ tabel dengan nilai $\mathrm{N}=35$ dicari pada distribusi nilai $\mathrm{r}$ tabel pada signifikansi 5\% maka diperoleh nilai $\mathrm{r}$ tabel sebesar 0,3388. Dari 37 item kuisener semuanya memiliki nilai Cronbach's Alpha > 0, 3388 , sehingga diambil kesimpulan kuisener dinyatakan reliabel. (Setyawarno: 2016).

Dari hasil kuisioner motivasi belajar diperoleh data bahwa dari 45 siswa yang berada dalam kelompok kelas eksperimen terdiri dari 22 siswa bermotivasi tinggi dan 13 siswa bermotivasi rendah, sementara di kelompok siswa kelas konvensional dari 35 orang siswa terdapat 18 siswa bermotivasi tinggi dan 17 siswa bermotivasi rendah. Secara keseluruhan terdapat 40 siswa bermotivasi tinggi dan 30 siswa bermotivasi rendah. Diambil kesimpulan secara umum siswa dalam kelas kontrol memiliki lebih besar siswa yang bermotivasi tinggi dibandingkan dengan kelas konvensional. Hal ini mungkin dipengaruhi oleh indikator dari motivasi belajar yaitu adanya keinginan atau hasrat untuk berhasil sehingga tumbuh kemauan untuk belajar didorong oleh adanya kegiatan yang menarik dalam belajar dan lingkungan yang kondusif, karena dapat dilaksanakan dimana saja. (Hikmawan:2018)

Selanjutnya untuk menentukan hasil belajar, alat uji sebelum digunakan dilaksanakan dulu uji pendahuluan terhadap Uji test hasil belajar. Uji normalitas digunakan untuk mengetahui normal tidaknya suatu distribusi data. Uji normalitas yang digunakan disini yaitu dengan uji Kolmogorof-Smirnov dengan alasan data yang akan diuji merupakan data tunggal bukan data distribusi frekwensi kelompok. Hal yang pertama dilakukan adalah menentukan taraf sigifikansi $(\alpha)=5 \%(0,05)$. Selanjutnya dari data yang diperoleh dengan bantuan program SPSS 
ver 20,0 diperoleh nilai Asymp.Sig(2-tailed =0,719). Karena nilai Asymp.Sig(2-tailed $=0,719)$ $\geq \alpha=0.05$ ditarik kesimpulan bahwa data terdistribusi Normal (Setyawarno: 2016).

Selanjutnya dilakukan uji Homogenitas untuk mengetahui apakah data penelitian dari populasi memiliki varians sama atau tidak, ui ini sebagai berfungsi sebagai syarat dalam analisis komparatif dengan uji ANOVA. Berdasarkan tabel 5 yang merupakan hasil output dari "Test of Homogeneity of Variances " diperoleh nilai untuk signivikansi variabel hasil Belajar Kimia pada siswa dengan menggunakan model belajar di kelas kontrol dengan kelas perlakuan adalah sebesar 0,131. Karena nilai Sig. $=0,131 \geq 0,05$ maka disimpulkan bahwa varians data hasil belanjar Kimia adalah sama, atau homogen. (Setyawarno: 2016). Karena varians bersifat homogen sehingga persyaratan dalam uji two way anova sudah terpenuhi.

Tabel 6. Merupakan tabel Tests of Between-Subjects Effects yang merupakan data output hasil dari subjek-subjek yang kita teliti. Dari tabel tersebut didapat

1. Untuk hasil pertama menunjukan terdapat pengaruh yang signifikan media pembelajaran terhadap hasil belajar kimia, dibuktikan dengan nilai sig. $0,000<\underline{\alpha}=$ 0,05 dan nilai $F_{\text {Hitung }}=24,744$

2. Terdapat pengaruh yang signifikan media motivasi belajar terhadap hasil belajar kimia, dibuktikan dengan nilai sig. $0,008<\alpha=0,05$ dan nilai $\mathrm{F}_{\text {Hitung }}=7,555$

3. Terdapat pengaruh interaksi yang signifikan media pembelajaran dan motivasi belajar terhadap hasil belajar kimia. dengan nilai sig. $0,022<\alpha=0,05$ dan nilai $F$ Hitung $=5,510$

Proses belajar mengajar di kelas merupakan inti pelaksanaan pembelajaran di sekolah, berbagai cara, tekhnik dan upaya yang dilakukan guru agar siswa cepat dapat mengerti, tahu dan mudah menautkan konsep-konsep yang ada dalam ranah kognitifnya. Salah satu cara yaitu dengan menggunakan media yang tepat, mudah dipelajari (oleh guru) dan sifatnya dapat menarik siswa agar mau belajar. Media dalam dunia pendidikan berfungsi sebagai sarana untuk menyalurkan pengetahuan dari guru ke peserta didik. Media pembelajaran menjadi bahan, alat atau tekhnik yang digunakan dalam kegiatan belajar mengajar, sehingga media pembelajaran memiliki manfaat yang besar dalam memudahkan siswa mempelajari materi pembelajaran. Media pembelajaran adalah sarana komunikasi dalam bentuk cetak maupun pandang dengar, termasuk perangkat keras, media pembelajaran adalah sarana fisik untuk menyampaikan isi materi pembelajaran. (Sumiharsono:2017)

Seiring berjalannya waktu dan perkembangan tekhnologi, kita sekarang berada dalam era komputerisasi. Komputer, gadget dan kuota merupakan perpaduan yang dapat memudahkan kita dalam melakukan 'sesuatu', ketiga hal tersebut membuat kita harus terus belajar agar menjadi bertambah cerdas dalam pemanfaatan tekhnologi. Pelaksanaan pembelajaran tidak terganggu dengan keharusan siswa melaksanakan PKL diluar sekolah, karena dengan kelengkapan media pembelajaran online(salah satunya) edmodo pembelajaran dapat dilakukan kapan saja dan dimana saja sesuai dengan setting yang dilakukan guru.

Media Edmodo juga membuat siswa lebih antusias terutama yang akan melaksanakan Praktek Kerja Industri. Antusiasme ini berdasar pengamatan bahwa dengan menggunakan Edmodo siswa lebih antusias karena pada saat mereka sedang melaksanakan PKL di industri, mereka tetap dapat membuka dan mempelajari materi kapan saja dan dimanapun juga sesuai dengan jadwal yang telah ditentukan guru. Karena sifat dari media Edmodo(online umummnya) dapat diakses kapan dan dimana saja selama ada kuota internet dan selama akses tidak ditutup oleh guru, demikian juga saat pelaksanaan tes/ujian. Hal ini sejalan dengan penelitian yang dilakukan Novitasari (2018) bahwa pembelajaran berbasis edmodo memberikan peningkatan motivasi siswa yang cukup signifikan dalam kegiatan proses pembelajaran dan siswa lebih aktif dan berujung pada meningkatnya nilai hasil belajar.

\section{KESIMPULAN}

Kesimpulan dari penelitian ini adalah bahwa selama siswa SMK sedang melaksanakan PKL yang berarti berada di industri, siswa dapat melaksanakan proses pembelajaran walaupun 
tidak dengan metode tatap muka, tapi setidaknya semua materi yang harus disampaikan tersampaikan. Adapun beberapa saran khususnya untuk teman-teman pengajar : (1). Dalam kegiatan proses belajar mengajar sebaiknya guru memilih dan menggunakan metode serta media pembelajaran yang tepat dan sesuai, serta menarik minat sehingga dapat memotivasi siswa untuk mau belajar. (2). Guru berusaha untuk selalu menambah pengetahuan dan mempelajari berubahnya serta berkembangnya media informasi yang terus berkembang. (3). Pemanfaatan perkembangan tekhnologi dan informasi ternyata berpengaruh dan dapat dimanfaatkan dengan sebaik-baiknya untuk proses pengajaran maupun administrasi pembelajaran.

\section{DAFTAR PUSTAKA}

Angkowo R. \& A. Kosasih. (2007). Optimalisasi media pembelajaran. Jakarta : PT. Grasindo Arikunto, Suharsimi. (2015). Dasar-dasar Evaluasi Pendidikan. Jakarta:Bumi Aksara.

Arsyad, Azhar. (2011). Media Pembelajaran. Jakarta: Rajawali Pers.

Jakni, S.Pd. (2016). Metodologi penelitian eksperimen bidang pendidikan. Bandung: Penebit fabeta.

Miarso, Yusufhadi,. (2004). Menyemai benih teknologi pendidikan. Jakarta: Kencana.

Nana Sudjana dan Daeng Arifin. (1988). Cara belajar siswa aktif dalam proses belajar mengajar. andung: Sinar Baru,

Novitasari dkk. (2017), Pengaruh Media Pembelajaran Berbasis Edmodo Terhadap Motivasi Siswa. Program Studi Pendidikan Biologi. Seminar Nasional Biologi, IPA dan Pembelajarannya I. Fakultas Keguruan dan Ilmu Pendidikan Universitas Muhammadiyah Jember. Hal 382-392.

Ruslan,.Tabrani A. (1994) Pendekatan dalam Proses Belajar Mengajar. Bandung: Remaja Rosda Karya,

Rusli Muhamad,.dkk. (2013). Multimedia Pembelajaran yang Inovatif: Prinsip Dasar dan Model Pengembangan. Denpasar: Penerbit Andi.

Sardiman, A.M., (2007). Interaksi dan Motivasi Belajar Mengajar: Bandung: Rajawali Pers

Setyawarno. (2016). Panduan Statistik Terapan Untuk Penelitian Pendidikan. Pendidikan IPA Universitas Negeri Yogyakarta

Slameto,(2003), belajar dan faktor-faktor yang mempengaruhinya. Jakarta: Rieneka

Sudjiono, Anas. (2012). Pengantar evaluasi pendidikan., Jakarta :Rajagrafindo Perkasa.

Sugiyono. (2014). Statistika untuk penelitian. Bandung: Penebit Alfabeta.

Sumiharsono, R., \& Hasanah H., (2017). Media pembelajaran. Jakarta: Pustaka Abadi.

Supardi, (2016). Aplikasi statistika dalam penelitian edisi revisi. Jakarta: Change Publication. ugihartono. (2007). Psikologi pendidikan. Yogyakarta: UNY Press.

Usman,. (2016). E-learning berbasis edmodo dalam pengajaran bahasa inggris pada jurusan akuntansi politeknik. JURNAL EKSIS Vol.12 No.1, April 2016: 3214 - 3345 from http://e-journal.polnes.ac.id/index.php/eksis/article/viewFile/44/23

W.S. Winkel. (1996). Psikologi pengajaran, Grasindo, Jakarta: PT. Raja Grafindo Persada, Widodo, (2017). Metodologi penelitian populer \& praktis. Jakarta.: Rajawali Pers, 